\title{
Meningokok Aş̧ıarı
}

\author{
Ayper SOMER*, Manolya ACAR*
}

\section{Meningokok Aşıları}

Meningokok hastalıklarl tüm dünyada yaygın görülen ve yaşamı tehdit eden tablolara neden olmaktadır. Polisakkarit meningokok assıları uzun yıllardır kullanımdadır ve hastalık sıklı̆̆ında azalma să̆lamıştır. Ancak, polisakkarit aşıların sütçocukları ve ufak çocuklarda zaylf immünojenite göstermesi, kısa süreli koruma sağlaması, immünolojik bellek geliştirmemesi, nazofarengeal taşıyıcılığa etki etmemesi ve yineleyen dozlarda azalmış yanıt sağlaması gibi önemli sorunları vardır. Polisakkarit aşıların kimyasal olarak konjügasyonu bu sorunların aşılmasını sağlamıştır. Günümüzde konjüge meningokok assları olarak kuadrivalan aşılar (MenACWY-DT, MenACWY-CRM ve MenACWYTT) ve monovalan A ve B aşıları bulunmaktadır. Kuadrivalan konjüge meningokok aşllarından MenACWY-TT (Nimenrix $\left.{ }^{T M}\right)$, tetanoz toksoit proteine konjüge edilmiş serogrup A, C, W ve Y içermektedir ve Avrupa'da 12. ayda tek doz olarak onay almış ilk meningokok aşısıdır. Yapılan çalışma sonuçları, MenACWY-TT aşısının sütçocuğu, çocuk, adolesan ve erişkinlerde tek doz uygulama sonrasi yeterli immünojenisite ve etkinlik profiline sahip olduğunu göstermektedir. Ayrıca güvenilirlik ve istenmeyen etki profili plasebo ile eşdeğerdir ve diğer aşılarla eşzamanlı olarak uygulanabilir.

Anahtar kelimeler: Meningokok aşıları, konjügasyon, kuadrivalan meningokok aşıları, çocuk

Çocuk Dergisi 2017; 17(3):93-98

\section{Meningococcal Vaccines}

Meningococcal disease is a serious and global lifethreatening disease. Meningococcal polysaccharide vaccines have been used for years and have led to the decline in the burden of the disease. However, polysaccharide vaccines have several limitations, including poor immunogenicity in infants and toddlers, short-lived protection, inability to develop immunologic memory, negligible impact on nasopharyngeal carriage, and induction of hyporesponsiveness after repeated doses. The chemical conjugation of plain polysaccharide vaccines has overcome these drawbacks. Meningococcal conjugate vaccines include the quadrivalent vaccines (MenACWY-DT, MenACWY-CRM, and MenACWYTT) as well as the monovalent $A$ and $C$ vaccines. The quadrivalent meningococcal conjugate vaccine (MenACWY-TT), comprising the serogroups $A, C, W$ and $Y$ conjugated to tetanus toxoid carrier protein (marketed under the trade name Nimenrix ${ }^{T M}$ ), is the first quadrivalent vaccine approved in Europe as a single dose for ages 12 months. Study results have demonstrated that MenACWY-TT has an adequate immunogenicity, and efficacy profile across a broad age range including toddlers, children, adolescents, and adults following its application. It has also a reliability, and side effect profiles equivalent to placebo, and it can be administered concurrently with other vaccines.

Keywords: Meningococcal vaccines, conjugation, quadrivalent meningococcal vaccines, child

J Child 2017; 17(3):93-98

\section{GíRiş}

İnvazif meningokok hastalıkları dünya genelinde mortalite ve morbiditenin önemli nedenlerinden biridir. Hastalık, etken mikroorganizmanın neden olduğu endotoksin ilişkili vasküler hasarın kontrolünün güç olması nedeniyle klinik olarak hızlı ve agresif seyretmektedir. Dünya genelinde tahmini olarak yılda 1.2 milyon meningokok enfeksiyonu gözlenmekte ve bu

\footnotetext{
Alındığı tarih: 17.10.2017

Kabul tarihi: 17.10.2017

* İstanbul Üniversitesi İstanbul Tıp Fakültesi Çocuk Enfeksiyon Hastalıkları Bilim Dalı

Yazışma adresi: Uzm. Dr. Manolya Acar, İstanbul Üniversitesi İstanbul Tıp Fakültesi, Çocuk Enfeksiyon Hastalıkları Bilim Dalı, Çapa / İstanbul

e-posta: manolya_kara@yahoo.com
}

vakaların 135.000 kadarı yaşamını kaybetmektedir (1). Ülkemizde 2009 sonrası Türkiye İstatistik Kurumu ölüm istatistiklerine bakıldı ̆̆ında, meningokok hastalığı ilişkili ölüm sayısı 154 olarak bildirilmiştir (2). Yaşayan kişilerde \%5-30 oranında sağırlık, konvülziyon, ekstremite ampütasyonu ve mental retardasyon gibi ciddi sekeller gözlenmektedir ${ }^{(3)}$.

Neisseria meningitidis' in neden olduğu meningokokal hastalık sıklığı yaşam boyu 3 kez artış göstermektedir. Bunlar, anneden geçen koruyucu antikorların tükendiği 1 yaş altı bebeklik, nazofarengeal taşıyıc1lığın yüksek olduğu adolesan ve immün sistemin zayıfladığı 65 yaş üstü yaşlılık dönemidir ${ }^{(4)}$. Etken, damlacık enfeksiyonu yoluyla bulaşmakta ve geç kış ile erken ilkbahar aylarında sıklığı artmaktadır. 
Meningokoklar bulaşı takiben, kısa süreli taşınabilmekte veya 1-14 gün içerisinde invazif hastalığa dönüşebilmektedir. Sağlıklı erişkinlerde taşıyıcılık \%10-25 arasında değişen düzeylere çıkabilmektedir. Ülkemizde yapılan çalışmalarda, taşıyıcılık oranının $\% 1.23$ ile \%21 arasında değiştiği bildirilmiştir ${ }^{(5,6)}$. Yakın zamanda yayınlanmış, Tekin ve ark. ${ }^{(7)} 10-24$ yaş arası 1518 adolesan ve genç erişkinde meningokok taşıyıcılığını araştırdığı çalışmalarında, N.meningitidis taşıyıc1lığ $\breve{1}_{1} \% 6.3$ olarak bulunmuştur.

N.meningitidis gram-negatif bir diplokok olup, en önemli virulans faktörü olan polisakkarit kapsüllerinin immünolojik reaktivitelerine göre 13 serogruba ayrılır. Bu serogruplar arasında insanlarda en sık invazif hastalık yapan serotipler A, B, C, Y, X ve W-135'tir. Serogrupların dağılımı coğrafi bölgelere ve yaş gruplarına göre değişiklik göstermektedir. Ceyhan ve ark.'nın (8) 2005-2012 yılları arasında ülkemizdeki bakteriyel menenjit etkenlerini değerlendirdikleri çok merkezli çalışmalarında, en sık $\% 51.6$ oranında N.meningitidis saptanmış, serotip dağılımında ise ilk iki sırada sırasıyla W-135 (\%38.1) ve B (\%26) belirlenmiştir. Benzer şekilde, Tekin ve ark.'nın ${ }^{(7)}$ çalışmasında, meningokok taşıyıcılarında saptanan en sik serotipler W-135 $(\% 66,6)$ ve B $(\% 9,4)$ olup, C serotipine rastlanmamıştır.

İnvazif meningokokal hastalık gelişimini önlemek için Aşı Uygulamaları Danışma Kurulu (Advisory Committee on Immunization Practices, ACIP)'nun aşılama önerileri Tablo 1'de belirtilmiştir ${ }^{(9)}$.

\section{Monovalan Aşılar}

Meningokok B serotipine karşı geliştirilmiş iki türlü aşı bulunmaktadır. Bunlar, Avrupa, Kanada, Avustralya ve ABD'de onaylanmış Bexsero (MenB4C) ve ABD'de onaylanmış Trumenba (MenB-FHbp) aşılarıdır. Bexsero'nun; 4 hafta ara ile 2 doz, Trumenba'nın ise iki doz (ilk dozdan 6 ay sonra ikinci doz) ya da 3 doz seri (0, 2-6. aylarda) şeklinde uygulanması önerilmektedir ${ }^{(13)}$.

\section{Bivalan Polisakkarit Aşılar}

Serogrup A ve C'nin polisakkaritini içermektedir. Aşı, bu iki gruba bağlı enfeksiyonlara karşı 3 yıl boyunca $\% 85$ koruyuculuk sağlamaktadır. Koruyucu antikor düzeyleri 3 yıldan sonra azalmaya başladığından, risk gruplarında aşının yinelenmesi önerilir. Tek doz olarak, $0.5 \mathrm{~mL}$, subkütan uygulanır. Aşılananların küçük bir bölümünde aşının uygulandığı bölgede ağrı, duyarlılık ve kızarıklık gibi lokal yan etkiler ile ateş, hâlsizlik ve baş ağrısı gibi sistemik reaksiyonlar görülebilir.

\section{Tetravalan Polisakkarit Aşılar}

MPSV4 (Meno-mune ${ }^{\mathrm{TM}} \mathrm{A} / \mathrm{C} / \mathrm{Y} / \mathrm{W}-135$ ) pürifiye meningokok kapsüler polisakkarit aşıdır. Subkutan yol ile $0,5 \mathrm{~mL} / \mathrm{doz}$ uygulamayı takiben $7-10$ gün sonra yeterli antikor yanıtı oluşmaktadır. Yolculuk öncesi ve askerlikte uygulanan aşı olarak günümüzde kullanılmaktadır. Mencevax ${ }^{\mathrm{TM}}$ (GlaxoSmithKline) tüm dünyada yaygın olarak kullanılan diğer polisakkarit meningokok aşıdır, ancak Amerika Birleşik Devletleri (ABD)'nde lisans almamıştır ${ }^{(14)}$.

\section{Konjüge Meningokok Aşıları}

Günümüzde ruhsatlanmış ve uygulanabilen konjüge meningokok aşıları: A serogrubu içeren MenAfriVac ${ }^{\mathrm{TM}}$ (Hindistan Serum Enstitüsü), C serogrubu içeren Meningitec $^{\mathrm{TM}}$ (Pfizer), Menjugate ${ }^{\mathrm{TM}}$ (GSK) ve NeisVac-C ${ }^{\mathrm{TM}}$ (Pfizer); A, C,W-135, Y serotiplerini içeren kuadrivalan aşılar Menectra ${ }^{\mathrm{TM}}$ (Sanofi-Pasteur), Menveo ${ }^{\mathrm{TM}}$ (GSK) ve Nimenrix ${ }^{\mathrm{TM}}$ (Pfizer)'dir ${ }^{(4)}$.

Tablo 1. ACIP meningokok aşılama önerileri.

11-18 yaş arası adolesanlar rutin olarak aşılanmalıdır (11-12 yaşlarında uygulanan ilk dozdan sonra 16 yaşında pekiştirme dozu ile).

İnvazif meningokok hastalığı açısından risk altındaki $\geq 2$ ay üstü bireyler rutin olarak aşılanmalıdır. Bunlar:

- Anatomik ya da fonksiyonel aspleni ya da kompleman (properdin, faktör D, faktör H ve C5-C9) eksikliği olan $\geq 2$ ay üstü bireyler,

- Aşısız ya da eksik aşılı popülasyonun yoğun olarak bulunduğu askeri kışla, yatılı okul gibi kurumlarda bulunanlar,

- Mesleki maruziyet riski olan mikrobiyologlar,

- Meningokok hastalığının hiperendemik ya da epidemik olduğu bölgede oturacak ya da bu bölgelere uzun süreli yolculuğa çıkacak olan $\geq 9$ ay üstï bireyler.

ACIP: Advisory Committee on Immunization Practices, Aşı uygulamaları Danısma Kurulu 


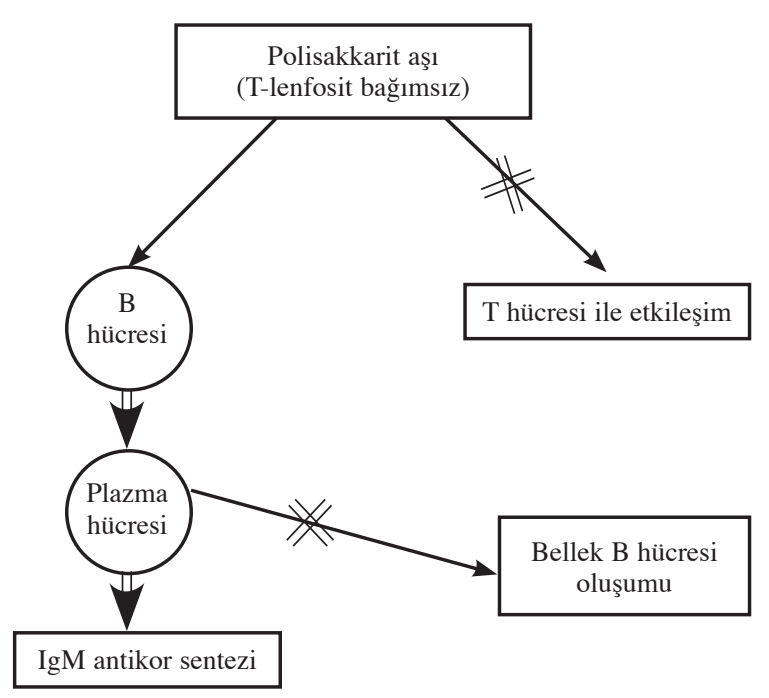

Şekil 1a. Polisakkarid aşıların bağışıklık uyarması.

MenACWY-DT (Menactra ${ }^{\mathrm{TM}}$ ); kapsül polisakkaritleri (A, C, W-135, Y) ile difteri toksoidi (DT) konjüge edilerek elde edilmiştir. 2005 yılında Amerikan Gıda ve İlaç Dairesi (Food and Drug Administration, FDA) tarafından onaylanmış ve 11-18 yaş grubundaki tüm adolesanlara ve risk grubunda olan 2-55 yaş arasındaki kişilere uygulanması önerilmiştir. Ekim 2005 tarihinde aşı yan etki bildirim merkezi, MenACWY-DT uygulanan 5 vakada Guillain-Barré Sendromu (GBS) geliştiğini bildirmiş, 2006 yılında aşılamadan sonraki ilk 6 hafta içinde GBS gelişen 11-19 yaş arası 15 vaka olduğu görülmüştür ${ }^{(15,16)}$. Bununla birlikte, yapılan değerlendirmelerde, meningokokal hastalık riskinin aşı ile ilişkili olabilecek GBS'ye göre çok daha fazla olması nedeni ile ABD Hastalık Kontrol ve Korunma Merkezi (Centers for Disease Control and Prevention, CDC) adolesanlarda rutin uygulamaya devam edilmesi gerektiği yönünde fikir bildirmiştir ${ }^{(17)}$. Amerikan Gıda ve İlaç Dairesi, 2011 yılında MenACWY-DT için 9 aylıktan itibaren uygulamaya onay vermiştir. Aşı, 9. ayda uyguland1ğında üç ay sonrasında ikinci doz uygulaması önerilmektedir.

Diğer konjüge aşı MenACWY-CRM (Menveo ${ }^{\mathrm{TM}}$ ) meningokok A, C, W-135 ve Y oligosakkaritlerinin non-toksik difteri proteini CRM197'nin N terminaline ve lizin amino grubuna kovalan bağlanmasıyla elde edilmiştir. 2010 yılı şubat ayında FDA tarafından 11-55 yaş arasında tek doz uygulama için onaylanmıştır. 2013 yılında FDA Menveo ${ }^{\mathrm{TM}}$ 'nun iki ay üzeri bebeklerde kullanılabileceğini belirtmiştir ${ }^{(18)}$.

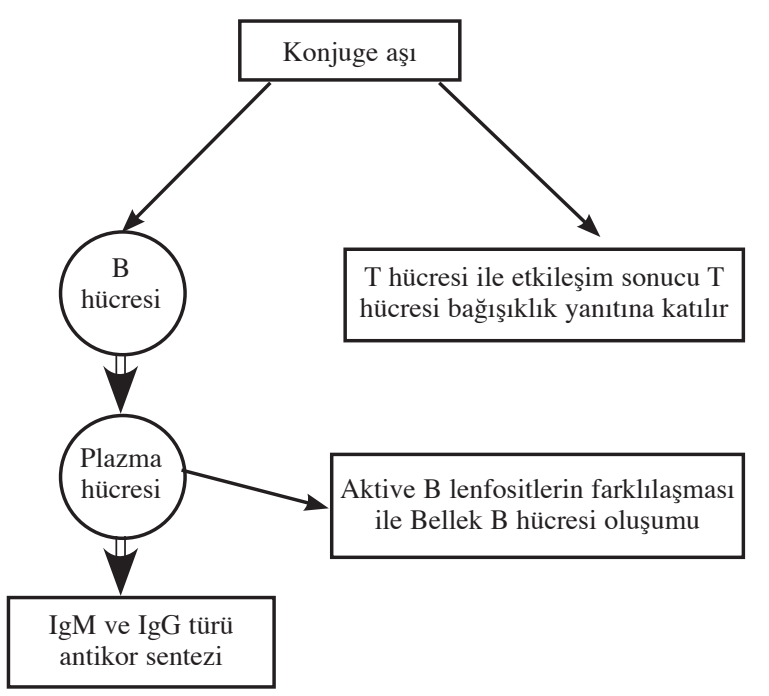

Şekil 1b. Konjüge aşıların bağışıklığı uyarması.

MenACWY-TT (Nimenrix ${ }^{\mathrm{TM}}$ ), meningokok A, C, W-135 ve Y serogruplarının tetanoz toksoid (TT) ile konjüge edilmesi ile geliştirilmiş diğer bir aşıdır. Adolesan, çocuk ve sütçocuklarında yapılan çalışmalarda aşının iyi tolere edildiği, immünojenisitesinin ve yan etki profilinin mevcut meningokok aşıları ile benzer olduğu gösterilmiştir. MenACWY-TT, Avrupa İlaç Ajansı (European Medicines Agency, EMEA) tarafından Nisan 2012'de onaylanmış olup, aşının Türkiye dâhil Avrupa'da 12 aydan büyük çocuk ve erişkinlerde tek doz intramüsküler olarak uygulanması önerilmektedir. Avrupa İlaç Ajansı 2016 yılında MenACWY-TT'nin iki aydan büyük bebeklere uygulanabilirliğini onaylamıştır.

MenACWY-TT; $0.5 \mu \mathrm{g}$ A,C,W-135 ve Y PS konjügatına ek olarak sükroz içinde $44 \mu \mathrm{g}$ tetanoz toksoidi (TT) ve trometamol içermektedir. Aşı $0,5 \mathrm{~mL}$ steril salinde çözündükten sonra intramüsküler yolla uygulanır ${ }^{(20)}$. Buzdolabında $2^{\circ} \mathrm{C}-8^{\circ} \mathrm{C}$ 'de saklanmalıdır. Sulandırıldıktan sonra $30^{\circ} \mathrm{C}^{\prime}$ de 8 saat etkinliğini koruduğu gösterilmiştir ${ }^{(19)}$.

Aşının immünojenik yanıtını değerlendiren çalışmalar farklı yaş gruplarında MenACWY-TT'nin etkinliğinin yüksek olduğunu göstermişlerdir. Pellegrino ve ark. ${ }^{(20)} 2015$ yılında yayınladıkları bir meta-analizde 15 randomize klinik çalışma incelemişler ve MenACWY-TT'nin test edilen tüm serotipleri için yüksek immünojenisite gösterdiğini saptamışlardır.

MenACWY-TT ile ilgili yürütülen antikor sürekliliği 
çalışmalarında sütçocukları, adolesan ve erişkinlerde aşılama sonrası koruyuculuğun 5. yıl sonunda istenilen düzeyde kaldığ gösterilmiştir $^{(21,22)}$. Vesikari ve ark. ${ }^{(23)}$ çalışmalarında, 12-23 ay arası MenACWYTT ile aşılanmış 304 çocuğun 229'unda aşılama sonrası serum koruyucu antikor titrelerinin (rSBA) 2. ve 3. yillarda sirasiyla $\% 93.6$ ve $\% 90.8$ oranında $\geq 1: 8$ düzeyde olduğunu saptamışlardır. Klein ve ark. ${ }^{(24)}$ 12. ayda tek doz ile 9 ve 12 . aylarda 2 doz aşı uygulamasını karşılaştırmışlar ve her iki grupta da A dışındaki diğer serotipler için bir yıl sonraki rSBA düzeyinin korunduğunu bildirmişlerdir.

MenACWY-TT aşısının çocuk, adolesan, erişkin ve 55-103 yaş arası popülasyonda da immünojenik ve güvenilir olduğu yapılan çalışmalarda gösterilmiştir ${ }^{(25-34)}$. Baxter ve ark.'nın ${ }^{(29)}$ çalışmasında, 10-25 yaş arası adolesan ve genç erişkinlerde tek doz MenACWY-TT aşısının immünojenik ve güvenilir olduğu saptanmıştır. Benzer şekilde 11-55 yaş arası çocuk ve erişkinlerde de tek doz aşının immünojenik ve güvenilir olduğu bildirilmektedir ${ }^{(22)}$. Dbaboi ve ark. ${ }^{(34)} 56$ yaş ve üzeri (en üst yaş 103) erişkinlerde yaptıkları çalışmada da benzer immünojenisite ve güvenilirlik verileri elde etmişlerdir.

Aşının güvenlik profili çeşitli yaş gruplarında irdelendiğinde, ciddi istenmeyen etki açısından kontrol aşılara göre istatistiksel farklılık saptanmamıştır. Aşılama sonrası bireylere lokal (ağrı, kızarıklık, şişlik) ve sistemik (yorgunluk, ateş, gastrointestinal semptomlar ve baş ağrısı) yan etkileri işaretledikleri ve semptomların şiddetlerinin 0-3 arası derecelendirdikleri bir anket verilerek yan etki değerlendirilmesi yapılmıştır. Knuf ve ark.'nın (28) çalışmalarında MenACWY-TT ile MenC-CRM197 (Meningitec ${ }^{\mathrm{TM}}$, Wyeth) ve PS aşıları (Mencevax ${ }^{\mathrm{TM}}$ ) karşılaştırılmış ve aşıların genel olarak iyi tolere edildiği, özellikle 12-14 ay ve 3-5 yaş arası grupta 3 . derece olarak belirtilen yan etki insidansının her grup için düşük olduğu ve bu yaş grubunda en sık saptanan lokal yan etkinin aşı yerinde kızarıklık gelişimi olduğu ifade edilmiştir. Dokuzuncu ayda aşılanan çocukların incelendiği diğer bir çalışmada, \%3.3 oranında ateş gözlenmiş olup, hiçbir vakada $>40^{\circ} \mathrm{C}$ 'nin üzerine çıkmadığı raporlanmıştır ${ }^{(24)}$. MenACWY-TT ve MenCCRM aşılarının etkinliğinin 12-24 ay arası çocuklarda karşılaştırıldığı diğer bir çalışmada, yan etki insidansı benzer bulunmuş olup, enjeksiyon yerinde kızarıklık ve huzursuzluk en sık bildirilen lokal ve sistemik istenmeyen etkiler olmuştur ${ }^{(23)}$. Adolesan ve erişkinlerde yürütülen çalışmalarda ise, en sık bildirilen lokal yan etki ağrı, sistemik yan etki ise yorgunluk ve baş ağrısı olarak raporlanmıştır ${ }^{(27)}$.

Birden fazla farklı aşının uygulanması gereken kişilere bu aşıların aynı vizitte uygulanabilir olması hasta uyumu ve immün yanıtın sağlanabilmesi açısından önemlidir ${ }^{(35)}$. Klinik faz 3 çalışmalarda MenACWYTT konjüge aşının influenza, hepatit $\mathrm{A}$ ve $\mathrm{B}$, konjüge pnömokok, difteri, tetanos, aselüler boğmaca, hepatit $\mathrm{B}$, inaktif polio, Haemophilus influenza tip b (Hib) konjüge aşısı gibi inaktif, kızamık kızamıkçık kabakulak ve suçiçeği aşısı gibi canlı aşılarla aynı zamanda uygulanmasının aşı yanıtı ve yan etki insidansı açısından fark yaratmadığı gösterilmiştir ${ }^{(4)}$.

\section{KAYNAKLAR}

1. Rouphael NG, Stephens DS. Neisseria meningitidis: biology, microbiology, and epidemiology. Meth Mol Biol 2012;799:1-20.

https://doi.org/10.1007/978-1-61779-346-2_1

2. T.C Başbakanlık Türkiye İstatistik Kurumu Ölüm İstatistikleri. Ölüm nedenlerinin cinsiyete göre dağıl1m1, 27/04/2017 tarihi itibariyle, 2009-2016. http:// www.tuik.gov.tr/PreTablo.do?alt_id=1083

3. Centers for Disease Control and Prevention (CDC). Licensure of a meningococcal conjugate vaccine (Menveo) and guidance for use - Advisory Committee on Immunization Practices (ACIP), 2010. MMWR Morb Mortal Wkly Rep 2010;59:273.

4. Assaf-Casals A, Dbaibo G. Meningococcal quadrivalent tetanus toxoid conjugate vaccine (MenACW-TT, Nimenrix $\left.{ }^{\mathrm{TM}}\right)$ : A review of its immunogenicity, safety, co-administration, and antibody persistence. Hum Vaccin Immunother 2016;12:1825-37.

5. Punar M, Çağatay AA, Özsüt H, Eraksoy H, Çalangu S, Dilmener M. İstanbul'da bir ilkokulda asemptomatik Neisseria meningitidis taşıyıcılığ Klimik Derg 2001;14:17-8.

6. Bakir M, Yagci A, Ulger N, Akbenlioglu C, Ilki A, Soyletir G. Asymptomatic carriage of Neisseria meningitidis and Neisseria lactamica in relation to Streptococcus pneumoniae and Haemophilus influenzae colonization in healthy children: apropos of 1400 children sampled. Eur J Epidemiol 2001;11:1015-8. https://doi.org/10.1023/A:1020021109462

7. Tekin RT, Dinleyici EC, Ceyhan M, Karbuz A, Salman N, Sutçu M. The prevalence, serogroup distribution and risk factors of meningococcal carriage in adolescents and young adults in Turkey. Hum Vaccin Immunother 2017;13:1182-9.

https://doi.org/10.1080/21645515.2016.1268304

8. Ceyhan M, Gürler N, Ozsurekci Y, Keser M, Aycan AE, Gurbuz V. Meningitis caused by Neisseria Meningitidis, Haemophilus influenzae Type b and 
Streptococcus pneumoniae during 2005-2012 in Turkey. A multicenter prospective surveillance study. Hum Vaccin Immunother 2014;10:2706-12. https://doi.org/10.4161/hv.29678

9. Prevention and Control of Meningococcal Disease: Recommendations of the Advisory Committee on Immunization Practices (ACIP). MMWR 2013;62 (RR02):1-22.

10. Croxtall JD, Dhillon S. Meningococcal quadrivalent (serogroups A, C, W-135 and Y) tetanus toxoid conjugate vaccine (Nimenrix). Drugs 2012;72:2407-30. https://doi.org/10.2165/11209580-000000000-00000

11. Miller JM, Mesaros N, Van Der Wielen M, Baine Y. Conjugate meningococcal vaccines development: GSK Biologicals Experience. Adv Preventive Med 2011; 2011:846756. https://doi.org/10.4061/2011/846756

12. Zlotnick GW, Jones TR, Liberator P. The discovery and development of a novel vaccine to protect against Neisseria meningitidis serogroup B disease. Hum Vaccines Immunotherapeutics 2015;11:5-13. https://doi.org/10.4161/hv.34293

13. Kim DK, Riley LE, Harriman KH. Recommended immunization schedule for adults aged 19 years or Older, United States, 2017. Ann Intern Med 2017;166:209. https://doi.org/10.7326/M16-2936

14. Department of Health \& Human Services fda/cber/ovrr/ dvrpa http://W-135W-135W-135.fda.gov/doW135 nloads/BiologicsBloodVaccines/Vaccines/ ApprovedProducts/UCM246961.pdf.

15. Centers for Disease Control and Prevention (CDC). Guillain-Barré syndrome among recipients of Menactra meningococcal conjugate vaccine--United States, JuneJuly 2005. MMWR Morb Mortal Wkly Rep 2005;54: 1023-25.

16. Centers for Disease Control and Prevention (CDC). Update: Guillain-Barré syndrome among recipients of Menactra meningococcal conjugate vaccine--United States, June 2005-September 2006. MMWR Morb Mortal Wkly Rep 2006;55:1120-24.

17. Centers for Disease Control and Prevention (CDC). Licensure of a meningococcal conjugate vaccine for children aged 2 through 10 years and updated booster dose guidance for adolescents and other persons at increased risk for meningococcal disease-Advisory Committee on Immunization Practices (ACIP), 2011. MMWR Morb Mortal Wkly Rep 2011;60:1018-9.

18. Novartis media release. FDA expands age indication for Menveo ${ }^{\circledR}$, first and only quadrivalent meningococcal vaccine for infants as young as 2 months of age. http://www.novartisvaccines.com/newsroom/mediareleases/2013/US_Menveo_Infant_FDA_Approval_ Press_Release_US.pdf.

19. GlaxoSmithKline Inc. Nimenrix_Meningococcal polysaccharide groups A, C, W-135 and Y conjugate vaccine. Product Monograph GlaxoSmithKline Inc 2015.

20. Pellegrinoa P, Perronea V, Radicea S, Capuanod A, Clementin E. Immunogenicity of meningococcal quadrivalent (serogroup A, C, W-135 and Y) tetanus toxoid conjugate vaccine: Systematic review and metaanalysis. Pharmacol Res 2015;92:31-9.

https://doi.org/10.1016/j.phrs.2014.10.006

21. Quiambao BP, Bavdekar A, Dubey AP, et al.
Antibody persistence up to $5 \mathrm{y}$ after vaccination with a quadrivalent meningococcal ACWY-tetanus toxoid conjugate vaccine in adolescents. Hum Vaccin Immunother 2017;13:636-44. https://doi.org/10.1080/21645515.2016.1248009

22. Borja-Tabora CFC, Montalban C, Memish ZA, et al. Long-term immunogenicity and safety after a single dose of the quadrivalent meningococcal serogroups A, $\mathrm{C}, \mathrm{W}$ and $\mathrm{Y}$ tetanus toxoid conjugate vaccine in adolescents and adults: 5-year follow-up of an open, randomized trial. BMC Infect Dis 2015;15:409. https://doi.org/10.1186/s12879-015-1138-y

23. Vesikari T, Forsten A, Boutriau D, Bianco V, Van der Wielen M, Miller JM. Randomized trial to assess the immunogenicity, safety and antibody persistence up to three years after a single dose of a tetravalent meningococcal serogroups A, C, W-135 and Y tetanus toxoid conjugate vaccine in toddlers. Hum Vacc Immunotherapeutics 2012;8:1892-903.

https://doi.org/10.4161/hv.22166

24. Klein NP, Baine Y, Bianco V, et al. One or two doses of quadrivalent meningococcal serogroups A, C, W-135 and $\mathrm{Y}$ tetanus toxoid conjugate vaccine is immunogenic in 9- to 12-month-old children. Pediatr Infect Dis J 2013;760-67.

https://doi.org/10.1097/INF.0b013e31828693c5

25. Dbaibo G, Macalalad N, Reyes MRA-DL, et al. The immunogenicity and safety of an investigational meningococcal serogroups A, C, W-135, Y tetanus toxoid conjugate vaccine (ACWY-TT) compared with a licensed meningococcal tetravalent polysaccharide vaccine: a randomized, controlled non-inferiority study. Hum Vaccin Immunother 2012;8:873-80.

https://doi.org/10.4161/hv.20211

26. Reyes MRA-DL, Dimaano E, Macalalad N, et al. The investigational meningococcal serogroups A, C, $\mathrm{W}-135$, Y tetanus toxoid conjugate vaccine (ACWYTT) and the seasonal influenza virus vaccine are immunogenic and well-tolerated when co-administered in adults. Hum Vaccin Immunother 2012;8:881-7. https://doi.org/10.4161/hv.20212

27. Ostergaard L, Lebacq E, Poolman J, et al. Immunogenicity, reactogenicity and persistence of meningococcal A, C, W-135 and Y-tetanus toxoid candidate conjugate (MenACWY-TT) vaccine formulations in adolescents aged 15-25 years. Vaccine 2009; 27: 161-8.

https://doi.org/10.1016/j.vaccine.2008.08.075

28. Knuf M, Kieninger-Baum D, Habermehl P, et al. A dose-range study assessing immunogenicity and safety of one dose of a new candidate meningococcal serogroups A, C, W-135, Y tetanus toxoid conjugate (MenACWY-TT) vaccine administered in the second year of life and in young children. Vaccine 2010;28:74453. https://doi.org/10.1016/j.vaccine.2009.10.064

29. Baxter R, Baine Y, Ensor K, et al. Immunogenicity and safety of an investigational quadrivalent meningococcal ACWY tetanus toxoid conjugate vaccine in healthy adolescents and young adults 10 to 25 years of age. Pediatr Infect Dis J 2011;30:e41-8. https://doi.org/10.1097/INF.0b013e3182054ab9

30. Vesikari T, Karvonen A, Bianco V, et al. Tetravalent meningococcal serogroups A, C, W-135 and Y conju- 
gate vaccine is well tolerated and immunogenic when co-administered with measles mumps-rubella-varicella vaccine during the second year of life: an open, randomized controlled trial. Vaccine 2011;29:4274-84. https://doi.org/10.1016/j.vaccine.2011.03.043

31. Memish ZA, Dbaibo G, Montellano M, et al. Immunogenicity of a single dose of tetravalent meningococcal serogroups A, C, W-135, and Y conjugate vaccine administered to 2- to 10 -year-olds is noninferior to a licensed-ACWY polysaccharide vaccine with an acceptable safety profile. Pediatr Infect Dis J 2011;30:e56-62.

https://doi.org/10.1097/INF.0b013e31820e6e02

32.KnufM,Pantazi-Chatzikonstantinou A,Pfletschinger U, et al. An investigational tetravalent meningococcal serogroups A, C, W-135 and Y-tetanus toxoid conjugate vaccine co-administered with Infanrix ${ }^{\mathrm{TM}}$ hexa is immunogenic, with an acceptable safety profile in 12-23-month-old children. Vaccine 2011;29:4264-73. https://doi.org/10.1016/j.vaccine.2011.03.009

33. Bermal N, Huang L-M, Dubey A, et al. Safety and immunogenicity of a tetravalent meningococcal serogroups $\mathrm{A}, \mathrm{C}, \mathrm{W}-135$ and $\mathrm{Y}$ conjugate vaccine in adolescents and adults. Hum Vaccine 2011;7:239-47.

https://doi.org/10.4161/hv.7.2.14068

34. Dbaibo G, El-Ayoubi N, Ghanem S, et al. Immunogenicity and safety of a quadrivalent meningococcal serogroups A, C, W-135 and Y tetanus toxoid conjugate vaccine (MenACWY-TT) administered to adults aged 56 years and older: results of an open-label, randomized, controlled trial. Drugs Aging 2013;30:30919.

https://doi.org/10.1007/s40266-013-0065-0

35. General recommendations on immunization-recommendations of the Advisory Committee on Immunization Practices (ACIP). MMWR Recommendations Reports 2011;60:1-64. 